\title{
No olho do furacão: contribuição ao debate sobre a residência multiprofissional em saúde
}

The eye of hurricane: contribution to the debate about the multiprofessional residence in health

El ojo del huracán: aportación a lo debate sobre residência multiprofesional en salud

Interessante abordagem conceitual, mas com uma limitação. Por que não reconhecer que os diferentes lugares não são monolíticos, mas também constituídos por múltiplos atores em processo de mútua afetação? Por que tentar caracterizar o Estado como o normativo-prescritivo, o residente como o produtorinovador, as entidades médicas como o masculino dominador-conservador? Por que não reconhecer que o processo é dinâmico, configurado por múltiplas apostas, de modo que compreender a trama de disputas importa para significar os diferentes discursos em diferentes momentos?

De todo modo, o tema - a Residência Multiprofissional em Saúde - é relevante e a abordagem instigante. Não falo de qualquer lugar. Sou "ator" implicado no processo. Anteriormente, como ocupante do lugar Ministério da Saúde, depois, do lugar movimento social, e, atualmente, em um dos "assentos" da Comissão Nacional de Residência Multiprofissional em Saúde.

Por que disputar a Residência como modalidade de formação? Qual a importância disso para a construção do SUS? Por que essa "bandeira" não tinha entrado na agenda política dos formuladores de política, apesar de a possibilidade legal de instituir a aprendizagem pelo trabalho (a especialização em área profissional) estar assegurada no âmbito da educação? Por que somente a categoria médica tinha sua "especialização em serviço" regulamentada e financiada com recursos públicos?

Por que a residência, essa modalidade de especialização pelo trabalho, é interessante? Considerando a importância que o trabalho vivo e as tecnologias leves têm dentro da organização do trabalho em saúde, a possibilidade de organizar a formação "em ato", no momento da produção do "encontro" entre trabalhador e usuário, é extremamente interessante. Ela pode ser usada hegemonicamente, subordinando as relações aos procedimentos. Mas também pode ser usada inventivamente, possibilitando a abertura para o desafio para ampliar a escuta, produzir novas tecnologias de cuidado, ampliar a construção compartilhada de projetos terapêuticos com a participação do usuário.

Se a especialização pelo trabalho é construída de modo articulado, envolvendo gestores, trabalhadores, residentes e usuários, ela pode se configurar como agenciamento em defesa da vida. Se envolve instituições formadoras e de serviço, pode contribuir para a inovação de práticas de saúde e de formação, num formato

${ }^{1}$ Médica. Linha de Micropolítica do Trabalho e o Cuidado em Saúde, Pós-Graduação de Clínica Médica, Universidade Federal do Rio de Federal do Rio de aneiro. Alameda Fernão Cardim, 317, apto. 71 Jd. Paulista, São Paulo, SP, Brasil. 01.403-020 laura.macruz@gmail.com 
raro na graduação (baseado no encontro entre as profissões, coisa rara na graduação, pensada sempre por profissão).

Por que importa abrir espaço para que exista legalmente e esteja articulada com outras iniciativas políticas em favor da inovação na formação e no trabalho em saúde? Porque para o SUS não é indiferente o perfil dos profissionais formados e é importante dispor de instrumentos legais para produzir políticas e mecanismos regulatórios que favoreçam a sintonia das iniciativas de formação com os princípios do SUS, e não sua captura pelos interesses privados (de um mercado ou de uma categoria profissional). Além disso, o impacto é rápido, pois os profissionais chegam logo ao mercado de trabalho, ajudando ativamente a fortalecer algumas possibilidades dentro de um modelo de atenção à saúde em disputa.

Por que tanta resistência dos médicos (ou ao menos de suas entidades) à possibilidade da residência multiprofissional? Muitas respostas possíveis. Por um lado, ao ser única propriedade de uma categoria, a residência médica viveu longos anos à margem das políticas públicas, orientada pelos interesses corporativos. A existência de uma outra residência, instituída por iniciativa das políticas públicas, abre claramente a possibilidade de regulação e de disputa de orientação. Há também disputa por recursos, pois também esta nova modalidade deverá, em alguma medida, ser financiada por recursos públicos (antes exclusivamente destinados à residência médica). Há também a defesa de um espaço privilegiado de formação para uma profissão que historicamente se sobrepõe às demais e contava com um mecanismo singular de reprodução, quem sabe agora ameaçado.

A instituição da Comissão Nacional de Residência Multiprofissional em Saúde aconteceu, assim como quando da criação da Comissão Nacional de Residência Médica, por obra da ação articulada de movimentos sociais. No caso da Residência Médica, foram os médicos-residentes, naquela época firmemente envolvidos nas lutas democráticas, os principais artífices do movimento que levou à regulamentação dessa modalidade de formação. No caso da Residência Multiprofissional, residentes, coordenadores de programa, preceptores, associações de ensino, representantes do controle social e gestores do SUS foram atores decisivos.

Os movimentos iniciais de regulamentação apontam no sentido de um diálogo permanente com o movimento. Há iniciativas interessantes, experiências inovadoras, mas também captura, repetição. $O$ Ministério da Saúde, antes propositor do movimento, agora declara que a especialização a distância é sua aposta preferencial, pois atinge mais gente, mais rapidamente e com menos recursos. Assim, minguam os recursos da saúde para apoiar programas multiprofissionais. Já o Ministério da Educação, antes praticamente um expectador, coloca-se mais ativamente no cenário, propondo a criação de programas multiprofissionais, articulados com o SUS, no âmbito dos hospitais universitários, dispondo-se a financiar bolsas para sua efetivação (que entende importantes para a inovação da atenção à saúde no âmbito dos hospitais de ensino).

No olho do furacão. Há muitas apostas e muitas possibilidades. De invenção e de captura. E múltiplos agenciamentos em operação!!!! 